Journal of Advanced Research in Materials Science

Journal homepage: www.akademiabaru.com/arms.html ISSN: 2289-7992

\title{
An Overview on Performance of Steel Slag in Highway Industry
}

\author{
M. M. A. Aziz ${ }^{1, *}$, M. Shokri ${ }^{1}$, A. Ahsan², H. Y. Liü ${ }^{3}$, L. Tay ${ }^{1}$, N. H. Muslim¹ \\ Faculty of Civil Engineering, Universiti Teknologi Malaysia (UTM), 81310 Skudai, Johor, Malaysia \\ Dept. of Civil Engineering, University Putra Malaysia, 43400 UPM Serdang, Selangor, Malaysia \\ 3 School of Engineering and ICT, University of Tasmania, Tasmania 7001, Australia
}

\begin{abstract}
Transportation and highway industry are going to use sustainable and recycling materials to address the two global issues: environment and energy. One of the materials is steel-furnace slag, a sustainable waste material, which includes two types, i.e. compound aggregate brings out as a consequence of Electric Arc Furnace (EAF) and Basic Oxygen Furnace (BOF). Steel slag can replace the traditional aggregates because it has a feature that almost same to those traditional aggregates and it is easily secure as a by-product from the steel industry. The recent experimental researches in preliminary studies have demonstrated chemical, mechanical and physical and properties of the steel slag. California bearing ratio (CBR) value of steel slag is between 200 and $300 \%$, whereas CBR of crushed aggregate is only from 80 to $100 \%$. Furthermore, asphalt mixture using steel slag presents better mechanical characteristics than those of the corresponding asphalt with $100 \%$ natural aggregate. Combination of $30 \%$ steel slag and $70 \%$ natural aggregates in bitumen mixture shows excellent performance as surface course of roads. Hence, operation of steel slag in road construction reduces land fill, saves natural resources and improves the strength of pavement to sustain a heavier and higher volume of vehicles. The overall purposes of this review paper are collecting chemical, physical and mechanical characteristics of steel slag for illustrating its performance, highlighting the previous studies on the use of steel slag in road construction and the effect of different percentage of steel slag upon pavement as a replacement for natural aggregates.
\end{abstract}

\section{Keywords:}

Sustainable pavement; steel slag;

environment; fatigue; rutting; creep; skid

resistance

Copyright @ 2020 PENERBIT AKADEMIA BARU - All rights reserved

\section{Introduction}

Nowadays the topic of steel slag is one of the most important issues especially in transportation and highway. Electric arc furnace (EAF) steel slag is an industry-produced artificial aggregate which, after suitable processing, constitutes an excellent material for the manufacture of wearing course in road construction industry [1]. The Nottingham County Surveyor, E. Purnell Hooley is the first person in England who introduces the use of blast furnace slag in asphalt in 1903 [2].

The molten steel slag solidifies at a pit area when it flows from the furnace. The slag consists mainly of a melted mixture of oxides of iron, silica, calcium, magnesia and alumina. Additionally, steel slag used in asphalt concrete comprises the recycling of a waste material; hence minimize the amount

\footnotetext{
*Corresponding author.

E-mail address: mzaman@utm.my (M. M. A. Aziz)
}

https://doi.org/10.37934/arms.67.1.110 
of material placed in Oregon landfills. Steel slag, a waste product of steel yield has been used widely in road construction, because it has similar hardness and to those typical coarse aggregates.

Sustainability is an important aspect of developed countries, and the transportation industry is constantly trying new and innovative ways to recycle materials. Steel slag is outcome of the steel making process and has a complex chemical structure, comprising mostly of oxides and silicates that are formed through the oxidation of various additives within the steel. There are two major methods of producing steel: The Basic Oxygen Furnace (BOF) process and the Electric Arc Furnace (EAF) process [3-5].

The properties of steel slag like chemical, physical, radiochemical, mineralogical, morphological, and textural characteristics are need to recognize hence appraised the suitability and reusing potential of steel slag in asphalt mixture production. Besides that, it is necessary to know how it can influence or interact with road construction as wearing course of the environmental system [6].

After suitable treatment, steel slag, which is industrially-produced artificial aggregate, constitutes an exceptional material for manufacture of wearing course in the road construction industry [7]. It should be noted that rutting, skid resistance and fatigue are the most destructive effects on structure of road especially on wearing course, and steel slag represents the excellent conceivable as a replacement for typical aggregates in road construction for preventing pavement deteriorations. Furthermore, normally steel slag is used in intersections, industrial roads and parking areas since high frictional and high wear resistance is obligatory there [8]. Figure 1 illustrates a flow diagram for discussion in this review paper.

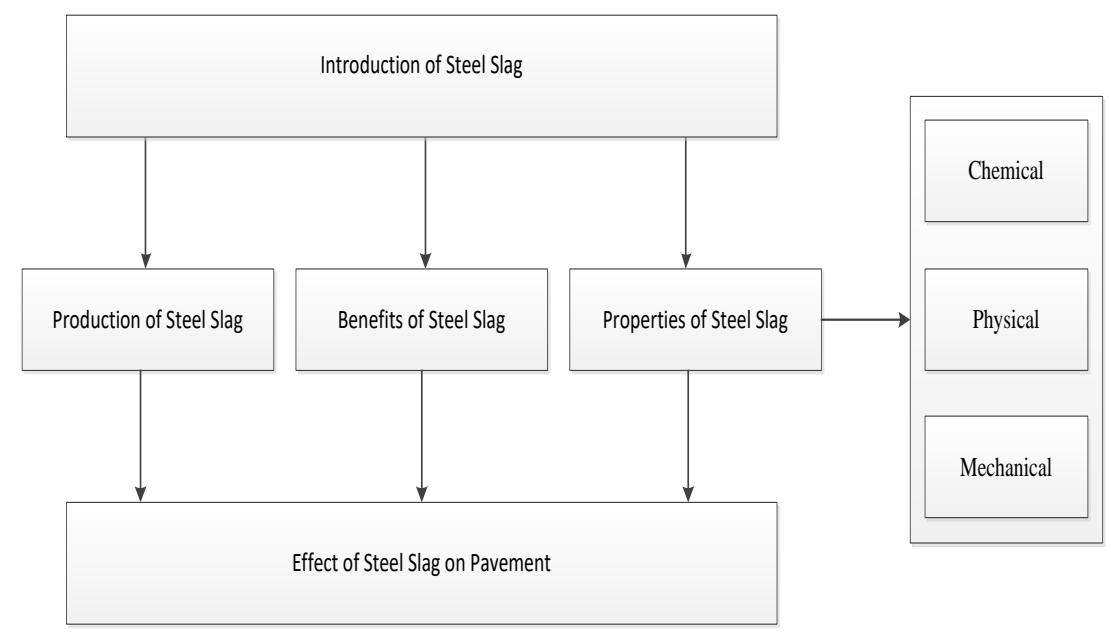

Fig. 1. Flowchart of discussion for this review paper

\section{Production of Steel Slag}

Usually steel slag consists of scarp (blast) furnace (BF) slag and steelmaking (iron making) slag. The steel furnace slag can be further divided into three groups; Basic-oxygen-furnace (BOF) slag, Electric-arc-furnace (EAF) slag and Ladle slag [5]. The product of the BOF is molten steel with a specified chemical analysis at $2900^{\circ} \mathrm{F}-3000^{\circ} \mathrm{F}$ [9]. In majority of the iron factory around the entire world, Oxygen converters are used to refine liquid pig iron and Electric Arc Furnaces are used to remelt scrap. Normally, steel slag is produced at the rate of $9-15 \%$ of the liquid steel made [2]. Figure 2 shows the steel slag aggregates from Mega Steel, Banting, Selangor, Malaysia. 
The main gradients of the steel slag are $\mathrm{Al}_{2} \mathrm{O}_{3}, \mathrm{Cr}_{2} \mathrm{O}_{3}, \mathrm{CaO}, \mathrm{MgO}, \mathrm{SiO}_{2}$, and $\mathrm{TiO}_{2}[6,10]$. In addition, it obviously consists of silicates, alumina silicates, calcium, iron oxides and crystalline compounds [11]. During the process of minimizing iron ore by coke in a blast furnace, BF slag is produced.

Its sources are the gangue content of iron ore, i.e. constituents of iron ore other than iron, and lime content added to modify the composition of molten slag. Steelmaking slag is a product of blast furnace into steel, by the process of refining hot metal, and has been mostly used as road material [12].

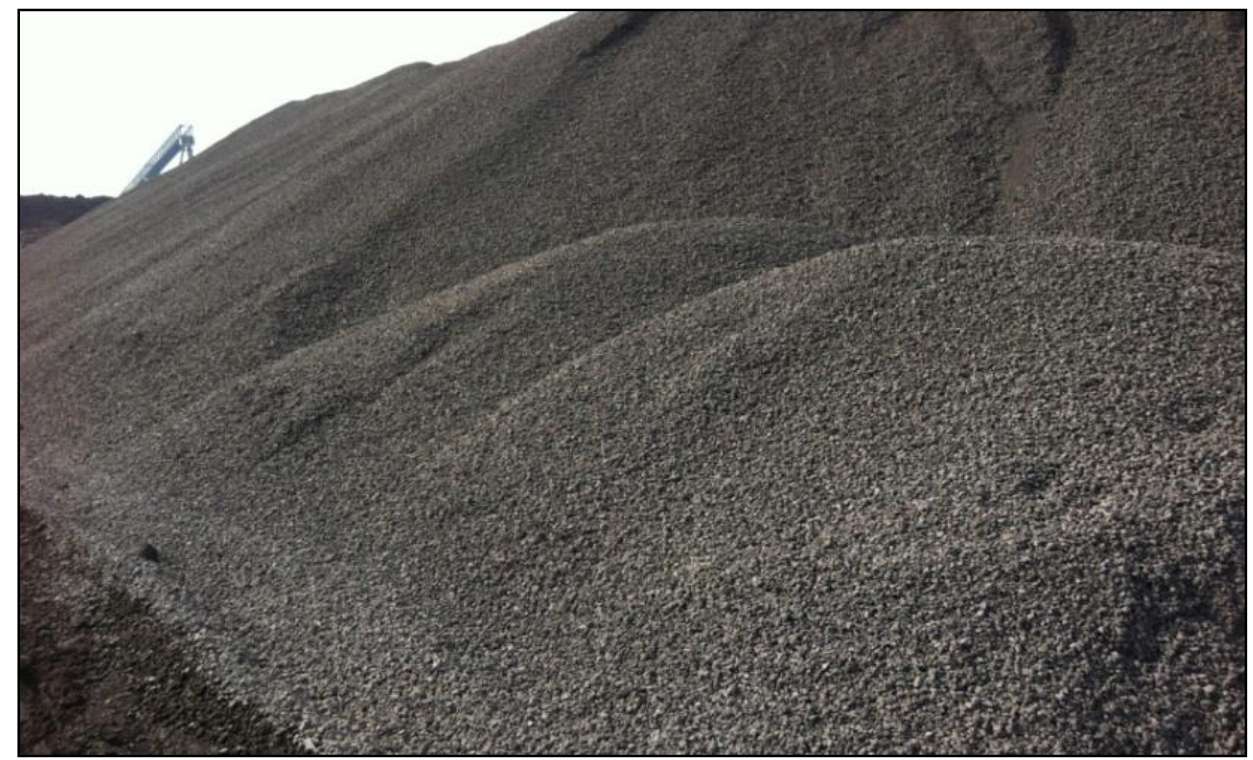

Fig. 2. EAF Steel slag aggregates from Mega Steel, Banting, Selangor, Malaysia

EAF mills produce steel mostly by remelting piece steel. In this process, input materials like scrap metal, iron ore and fluxing agents such as lime are appointed to a furnace, refined, and heated further than their melting points [13]. Two or more liquids have been formed when these materials arrive at a state of complete fusion. Slag is a layer that forms on the surface of melt at the lowest specific gravity [14].

\subsection{Properties of Steel Slag}

Information of the mineralogical, and morphological properties of steel slag is necessary because of their chemical, physical and mechanical properties may play a key role in their utilization [5]. Optical Microscopy (OM), X-Ray Diffraction (XRD), Scanning Electron Microscopy (SEM) and Energy Dispersive Spectrometry (EDS) are engaged to study the consistency, morphology and composition of steel slag [6].

\subsection{Physical and Chemical Properties}

Different properties of various aggregates influenced their level of performance and suitability for an application. The physical and mechanical characteristic of an aggregate played an important role in providing the ideal durability, permeability, stability, resistance against abrasion, cracking and permanent deformation. Besides, the chemical composition of an aggregate was continuously studied and found to be a factor affecting its adhesion with other construction material to form an ideal combination [15]. EAF has the satisfied durability, physical and mechanical properties which 
reveal it is suitable to be used in roads, airport and other pavement area as it fulfils the term requisite for aggregates apply for bituminous mixtures and surface treatments [6]. Steel slag aggregates are extremely in rough surface texture and angular in shape. Moreover, they possess high bulk specific gravity and reasonable water absorption (less than 3 percent).

Slag has chemical composition which is frequently present in terms of simple oxides calculated from elemental analysis on the basis of $x$-ray fluorescence. Moreover, the rate of slag cooling in the steel-making process will affect the mineralogical form of the slag [6, 16-17].In addition, the neutralization capacity of the steel slag was highest above $\mathrm{pH} 8.5$ and lower in the weakly alkaline or neutral $\mathrm{pH}$ range, approximately less than 12 [18]. Generally Steel slag samples release neither temperature nor gases in reaction with water, and their water solubility is rather poor. Reaction $(\mathrm{pH})$ of the observed materials is alkali ( $\mathrm{pH}$ between 11.09 and 12.27) [19].

\subsection{Bitumen Binder}

Bitumen is a non-crystalline, viscoelastic and rheological material, black or dark brown, which is substantially soluble in carbon di-sulphide $\left(\mathrm{CS}_{2}\right)$, possessing adhesive and water-proofing qualities. Besides, the physical and chemical properties of bitumen binder, it possesses a unique and fundamental microwave properties (permittivity). It is a lowloss material as loss tangent, $\tan \delta\left(\varepsilon^{\prime \prime} / \varepsilon^{\prime}\right)$ $<0.5$ and its microwave permittivity (dielectric constant, $\varepsilon^{\prime}$ ) value ranges from 2 to 7 depending on grade of bitumen, asphaltenes content, temperature and microwave frequency [20]. It includes basically of hydrocarbons and normally comprises of at least $80 \%$ carbon and $15 \%$ hydrogen, the remainders are being nitrogen, sulphur, oxygen, and traces of various metals. The reason of its use as binder in flexible pavement is its viscoelastic behaviour.

\subsection{Mechanical Properties}

EAF was used to the mechanical tests for its durability, physical, geometric and mechanical properties to determine the acceptable of steel slag in the production of asphalt mixture The results of those tests have been used to compare with typical aggregates normally applied in the manufacture of asphalt mixtures [6].

It is found that the processed steel slag has suitable mechanical properties, good soundness characteristics, better abrasion resistance and high bearing strength compared with natural aggregates. Table 1 summarizes the physical, chemical and mechanical properties of the steel slag.

\section{Effect of Steel Slag on Pavement Industry}

\subsection{Fatigue Cracking}

Road for high speed traffics suffers from recycling and alternative stress in its service life, leading to fatigue destruction [22]. Steel slag is useful for advancing the properties of asphalt mixtures for fatigue life and stability [23]. Louzi developed a model to determine the number of repetitions at an primary strain at any stage for each design method each percentage of steel slag [23]. Louzi [23] added three percentages of steel slag into the lime stones (15\%,30\% and $45 \%)$, tested these samples at different primary tensile strain levels, and recorded the sample failure at which cycles. It was found that all percentages of steel slag with mixture of lime stone have better performance compare with SUPERPAVE (SUperior PERformance asphalt PAVEment) and Marshal during the stability and Indirect Tensile Strength test. 
Table 1

Chemical, physical and mechanical properties of steel slag

\begin{tabular}{|c|c|c|c|c|c|c|c|c|}
\hline \multirow[t]{2}{*}{ Constituent } & \multirow{2}{*}{$\begin{array}{c}\text { Ameri et } \\
\text { al.[3] } \\
\text { (EAF) }\end{array}$} & \multirow{2}{*}{$\begin{array}{c}\text { Chaurand } \\
\text { P. et al.[21] } \\
\text { (BOF) }\end{array}$} & \multirow{2}{*}{$\begin{array}{c}\text { T. sofilic } \\
\text { et al.[6] } \\
\text { (EAF) }\end{array}$} & \multicolumn{2}{|c|}{ Yildirim et al.[5] } & \multirow{2}{*}{$\begin{array}{l}\text { joulazadeh.m } \\
\text { et al. [11] } \\
\text { (BOF) }\end{array}$} & \multicolumn{2}{|c|}{$\begin{array}{c}\text { Mohd Abd Wahab } \\
\text { Yusof }\end{array}$} \\
\hline & & & & (BOF) & (EAF) & & (EAF) & (BOF) \\
\hline $\mathrm{CaO}$ & $50 \sim 57$ & 41.3 & 33.22 & 39.4 & 47.52 & 45.2 & $30 \sim 40$ & $45^{\sim} 55$ \\
\hline $\mathrm{Fe} 2 \mathrm{O} 3$ & $10^{\sim 13}$ & 31.2 & 29.64 & - & - & 12 & - & - \\
\hline $\mathrm{FeO}$ & $15^{\sim 19}$ & - & - & 30.23 & 7.61 & 7.4 & - & - \\
\hline $\mathrm{SiO} 2$ & $9 \sim 11$ & 12.5 & 11.01 & 11.97 & 4.64 & 14.6 & $12^{\sim} 17$ & $12^{\sim} 18$ \\
\hline $\mathrm{Al} 2 \mathrm{O} 3$ & $1.4 \sim 0.7$ & 2.4 & 1.66 & 2.16 & 22.59 & 3.9 & $4 \sim 7$ & $<3$ \\
\hline $\mathrm{MgO}$ & $1 \sim 2$ & 4.3 & 13.09 & 9.69 & 7.35 & 4.9 & $4 \sim 8$ & $<3$ \\
\hline $\mathrm{MnO}$ & $4 \sim 5$ & 6.1 & 6.18 & 2.74 & 1 & 4 & $<6$ & $<5$ \\
\hline $\mathrm{P}_{2} \mathrm{O}_{5}$ & $3.2 \sim 2.3$ & 1.1 & - & 1 & - & - & - & - \\
\hline $\begin{array}{c}\text { Water } \\
\text { absorption }\end{array}$ & 2.9 & - & 1.6 & - & - & $0.30 \%$ & $0.2 \sim 2 \%$ & $0.2 \sim 2 \%$ \\
\hline Density & $\begin{array}{c}3250 \\
(\mathrm{~kg} / \mathrm{m} 3 \\
)\end{array}$ & - & $\begin{array}{c}3.4 \\
(\mathrm{mg} / \mathrm{m} 3)\end{array}$ & - & - & $3.21(\mathrm{~kg} / \mathrm{cm} 3)$ & $\begin{array}{c}1600 \\
\sim 1920\end{array}$ & $\begin{array}{c}1600 \\
\sim 1920\end{array}$ \\
\hline PSV & - & - & 54.7 & - & - & $970(\mathrm{~kg} / \mathrm{cm} 2)$ & $53 \sim 72$ & $53 \sim 72$ \\
\hline AAV & - & - & 8 & - & - & - & $3 \sim 4$ & $3 \sim 4$ \\
\hline SG & - & - & - & - & - & - & $3.1 \sim 3.5$ & $3.1 \sim 3.5$ \\
\hline LAV & 18 & - & 16 & - & - & - & $20 \sim 25$ & $20 \sim 25$ \\
\hline
\end{tabular}

EAF: Electric arc Furnace, BOF: Basic-oxygen-Furnace, PSV: Polished Stone Value, AAV: Aggregate Abrasion Value, LAV: Los Angles Value, SG: Specific Gravity

\subsection{Rutting Deformation}

Mixtures containing steel slag as coarse aggregates are more resistant to permanent deformation and have lower rutting depth [23]. According to Wang et al. (2011), the average rutting depth of the granite specimens is $6 \mathrm{~mm}$ at the end of the test, while the average depth of the steel slag specimens is $2 \mathrm{~mm}$ [24].

Both mixtures meet the typical rut depth criterion, but the mixture made of steel slag demonstrates a much less rutting potential than that made of granite. In addition higher rutting resistance occurred because of the higher creep stiffness of the mixtures with steel slag as coarse aggregate [8].

Muniandy et al. (2012) [25] evaluated the effect of different portions of steel slag on rutting. Figure 3 illustrates their results where, S0 is Steel slag filler fraction 100\% passing 20 micron sieve, S5 is Steel slag filler fraction 50/50 \% passing 75/20 micron sieve and S10 is Steel slag filler fraction $100 \%$ passing 75 micron sieve [24]. 


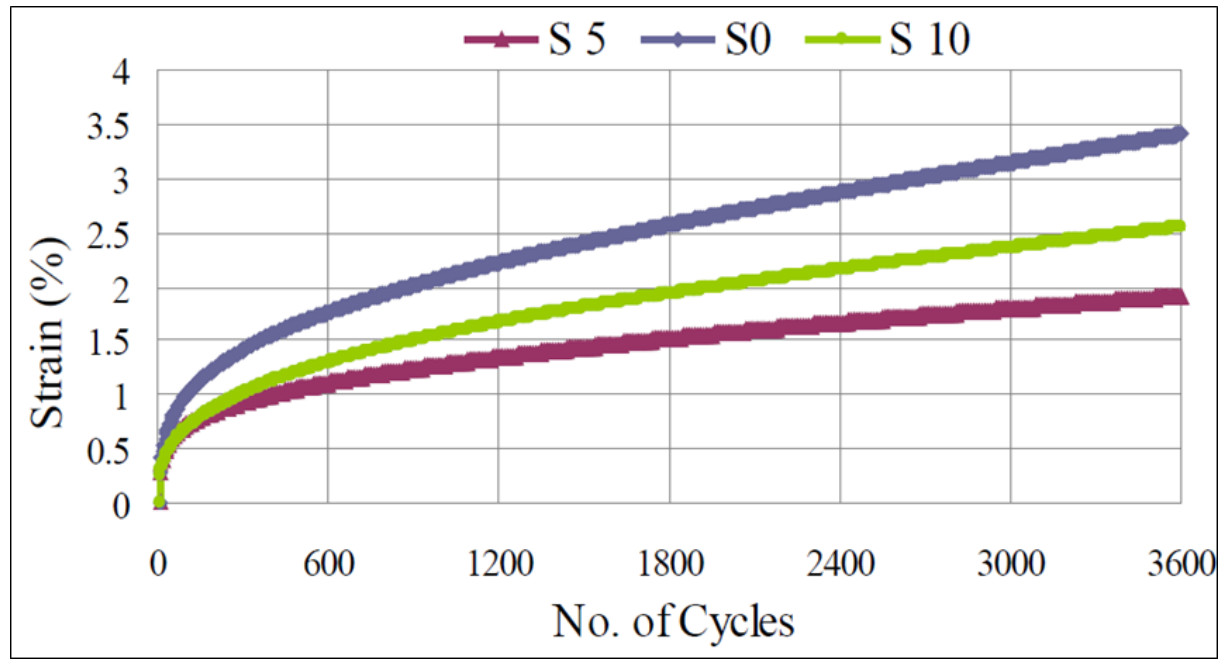

Fig. 3. Axial strain versus number of load cycles for SMA Mix with steel slag filler

\subsection{Resilient Modulus Due to Ageing}

The resilient modulus of both asphalt mixture with $100 \%$ steel slag and that with equal content of granite aggregates and steel slag increases due to oxidation of the binder after short-term oven aging [25]. The resilient modulus of $100 \%$ steel slag mixes is higher than that of $50-50 \%$ mixes both before and after ageing. However, the resilient modulus of both mixes (100\% and $50-50 \%)$ at increment temperature of range from $10^{\circ} \mathrm{C}$ to $40^{\circ} \mathrm{C}$ decreases nearly $90 \%$ [25].

Resilient modulus of steel slag is better than conventional wearing course since the steel-slag mixture yields a higher resilient modulus compared to the conventional mixture at both room and high temperatures. Resilient moduli of steel slag and conventional wearing course at $25^{\circ} \mathrm{C}$ are determined to be $4436.15 \mathrm{MPa}$ and $1976.85 \mathrm{MPa}$ respectively while they are $471.35 \mathrm{MPa}$, and 268.15 MPa, respectively, at $40^{\circ} \mathrm{C}$. Figure 4 illustrates comparing between steel slag and conventional wearing course in resilient modules test [26], which indicates that when steel-slag is used as wearing course, its resilient modulus is almost twice that of conventional aggregate [27].

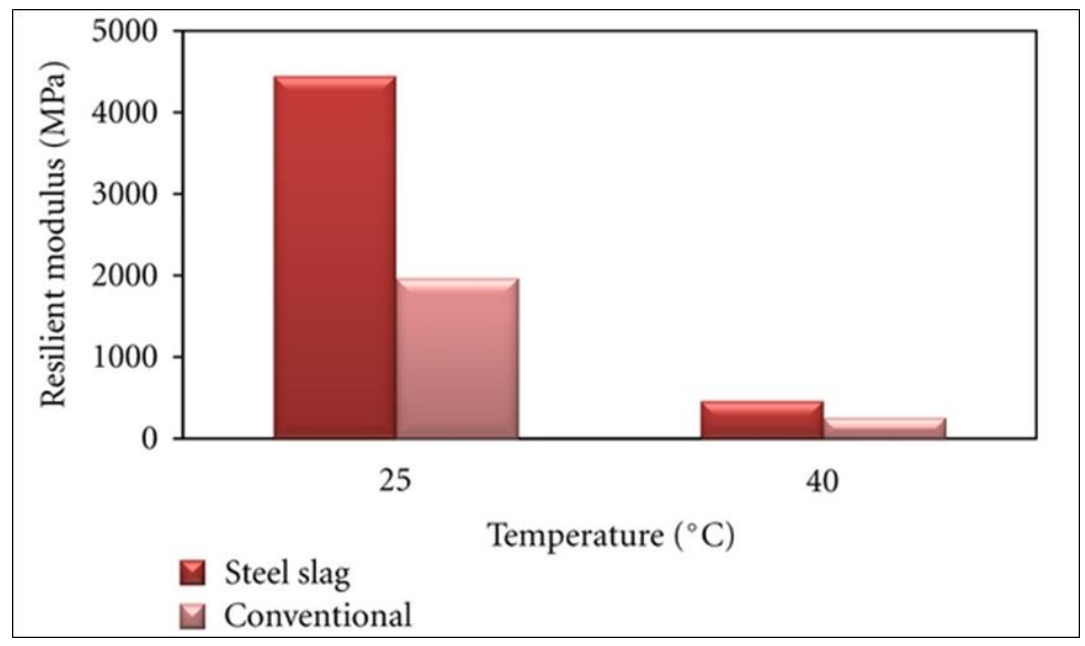

Fig. 4. Comparing between steel slag and conventional wearing course in resilient modules test 


\subsection{California Bearing Ratio (CBR)}

Very high values of CBR, e.g. up to 210 have been recorded for some steel slag blends in literature[26]. Moreover, it is found that the SSA (steel slag aggregate) mixes have produced a base course that is not only water-insensitive has but also very high CBR values. In addition, it is noted that the CBR of the steel slag aggregates with different type of mixture with natural aggregates is different and varies around $400[28]$.

\subsection{Skid Resistance}

The variables such as surface aggregate factors, load factors, environmental factors and vehicle factors are affected the measurement the level of skid resistance and their inter-relationships are complex. Surface aggregate factors is preferred to surface macrotexture and microtexture and geological properties of the aggregate, and load factors are the traffic intensity, surface age, composition and flow status, and road geometry. In the other hands, environmental factors such as short term rainfall effects, water film thickness, temperature, surface contamination, and seasonal also affect the measurement the level of skid resistance. Meanwhile, vehicle factors are preferred to vehicle speed, wheel slip ratio, angle of tyres, tread depth and patterns and tyre characteristics, [29].

In ASTM test method E274, the skid number (SN) is defined to be equal to $100 * \mathrm{f}$, where $\mathrm{f}$ is friction factor [30]. The friction factor is equal to $F / L$, where $F$ is motion frictional resistance and $L$ is load perpendicular to the interface [30]. Bitumen with 30\% slag have the highest SN followed by Superpave, SMA (stone matrix aggregate), and Marshall mixes[30]. Figure 5 shows the skid numbers among different asphalt concrete mixes.

Thus, asphalt concrete with steel slag can be contrived to ameliorate skid resistance of road appearance, particularly at highway crossings [30].

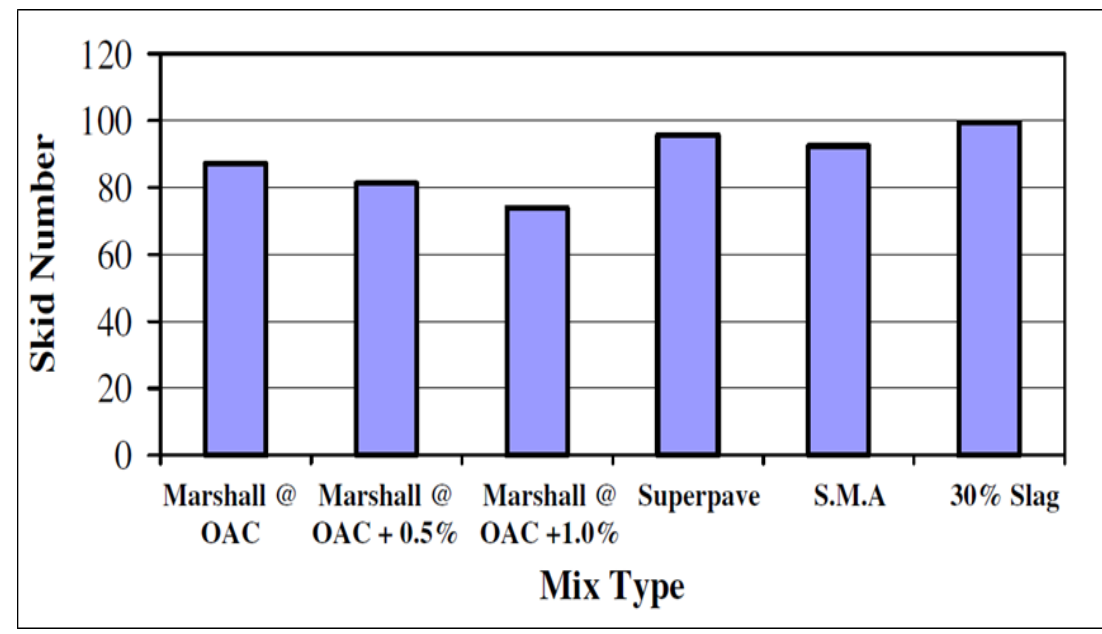

Fig. 5. Comparison of different asphalt concrete mixes in terms of skid numbers [30]

\subsection{Specific gravity}

As a rule, the specific gravity decreases when the slag particle size increases [31]. Based on Wang et al.'s study (2010), specific gravity of BOS slag is around $3 \mathrm{~g} / \mathrm{cm} 3$ [32].

Generally, mixtures with steel slag have shown encouraging results in comparison with those containing limestone. Moreover, it is found that the replacement of the coarse portion of limestone aggregate with steel slag leads to better results in comparison with the mixtures that contain steel 
slag as the fine portion $[8,23]$. Furthermore, steel slag mix is required more energy to heat to reach given temperature than typical aggregate because the steel slag mix clasp longer heat hence cools slower [31]. Besides, steel slag has excellent performance comparing to SMA (stone mastic asphalt) made of basalt [33]. Finally, It should be mentions that the steel slag mixture is more flexible in low temperature and more rigid in high temperature [34].

\subsection{Creep}

The creep test determines permanent deformation of asphalt mixtures. The static load is measured as a function of time, while the mixture dimensions and test conditions are standardized. Figure 6 illustrates the results for the deformation and strain of wearing course. It is clear that deformation and strain of the steel-slag mixture with lime stone is lower than those of the conventional mixture wearing course. Permanent deformation of the steel-slag mixture has been determined to be $0.044 \mathrm{~mm}$, whereas it is $0.605 \mathrm{~mm}$ for the conventional mixture. The strain for the steel-slag mixture has been measured as $0.377 \%$ and it is $0.946 \%$ for the conventional mixture. The steel-slag mixture has perfect performance in terms of interconnecting and adhesion. Thus, the steelslag mixture demonstrates that it can resist better deformation and can last longer when compared to the conventional wearing course [27]. Figure 6 shows performance of steel slag and conventional wearing course in the creep test [26].

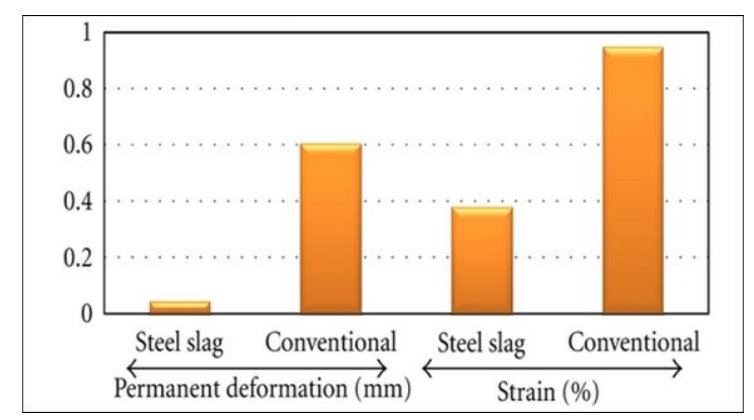

Fig. 6. Illustrates performance of steel slag and conventional wearing course in creep test [27]

\section{Recommendation}

The use of artificial or recycled materials becomes more and more attractive in highway construction nowadays. Steel slag may be one of the best substitutes of artificial aggregates for road construction, which can not only help save the friendly environment and but also provides an artificial material with higher resistance. In this review paper, firstly, some important characteristics of steel slag mixture including chemical, physical and mechanical properties were highlighted, and secondly, effects of steel slag upon pavement in comparison with conventional asphalt mixture were evaluated. Generally, the use of steel slag aggregates in asphalt mixture able to bring benefits in many ways. It outperforms many natural aggregates in terms of rutting, fatigue and stiffness resistance of the pavement. Furthermore, the average TSR ratio of the steel slag mixture is less than that of granite mixture and its stripping is very slight. Moreover, skid number of asphalt mixture including $30 \%$ steel slag is around 100, which is bigger than that of Stone Mix Asphalt (SMA). That is why addition of steel slag in asphalt mixture improves skid resistance of road surfaces. Finally, it is concluded that, in the 
rutting, fatigue, skid resistance, creep and resilient modules tests, the performance of steel slag mixture wearing course is better than that of the conventional wearing course.

\section{Acknowledgement}

Authors would like to thank Shell Singapore for bitumen supply and Universiti Teknologi Malaysia (UTM) for research grant (Vote No. 09H33) for this study, which is very much appreciated

\section{References}

[1] Liapis, loannis, and Spiraggelos Likoydis. "Use of electric arc furnace slag in thin skid-resistant surfacing." ProcediaSocial and Behavioral Sciences 48 (2012): 907-918.

[2] Holliday, K. A. "Steel slag: the high performance industrial aggregate." In PROCEEDINGS OF THE XIIITH WORLD MEETING OF THE INTERNATIONAL ROAD FEDERATION, TORONTO, ONTARIO, JUNE 16 TO 20, 1997. 1997.

[3] Ameri, Mahmoud, Hossein Shahabishahmiri, and Sanaz Kazemzadehazad. "Evaluation of the use of steel slag in concrete." In ARRB Conference, 25th, 2012, Perth, Western Australia, Australia. 2012.

[4] Tu, Huizhao, Hao Li, Hans Van Lint, Victor Knoop, and Lijun Sun. "Macroscopic travel time reliability diagrams for freeway networks." Transportation research record 2396, no. 1 (2013): 19-27.

[5] Yildirim, Irem Zeynep, and Monica Prezzi. "Chemical, mineralogical, and morphological properties of steel slag." Advances in Civil Engineering 2011 (2011).

[6] Sofilić, Ana Mladenovič Tahir. "Characterization of the EAF steel slag as aggregate for use in road construction." In CISAP4, 4th international conference on safety \& environment in process industry. 2010.

[7] Adesiyun, A., L. Arnaud, and N. Bueche. NR2C-New Road Construction Concepts. Towards reliable, green, safe\&smart; and human infrastructure in Europe. Part A: From the vision to developments required. No. REP_WORK. 2008.

[8] Ahmedzade, Perviz, and Burak Sengoz. "Evaluation of steel slag coarse aggregate in hot mix asphalt concrete." Journal of hazardous materials 165, no. 1-3 (2009): 300-305.

[9] J. Stubbles, The Basic Oxygen Steelmaking (BOS) Process. American Iron and Steel Institute (2013).

[10] Mostafaee, Saman. "A study of EAF high-chromium stainless steelmaking slags characteristics and foamability." PhD diss., KTH Royal Institute of Technology, 2011.

[11] Joulazadeh, M., and F. Joulazadeh. "Slag; value added steel industry byproducts." (2010): 1137-1145.

[12] Takahashi, Tatsuhito, and Kazuya Yabuta. "New application of iron and steelmaking slag." NKK TECHNICAL REPORTJAPANESE EDITION- (2002): 43-48.

[13] Wintenborn, J. L., and J. J. Green. "Steelmaking slag: a safe and valuable product." National Slag Association (1998).

[14] Dippenaar, R. "Industrial uses of slag (the use and re-use of iron and steelmaking slags)." Ironmaking \& steelmaking 32, no. 1 (2005): 35-46.

[15] Yi, TeohCherh. "Performance evaluation of steel slag as natural aggregates replacement in asphaltic concrete." PhD diss., MSc. Thesis, Universiti Sains Malaysia, 2008.

[16] Airey, Gordon D., Andrew C. Collop, and Nicholas H. Thom. "Mechanical performance of asphalt mixtures incorporating slag and glass secondary aggregates." In Proceedings of the 8th Conference on Asphalt Pavements for Southern Africa (CAPSA'04), South Africa, vol. 12, p. 16. 2004.

[17] Khanzadi, Mostafa, and Ali Behnood. "Mechanical properties of high-strength concrete incorporating copper slag as coarse aggregate." Construction and building materials 23, no. 6 (2009): 2183-2188.

[18] Weymouth, Thomas Sandy. "Evaluation of characterization techniques for beneficial use of underutilized slag materials." (2006).

[19] A. Rastovčan-Mioč, T. Sofilić, B. Mioč, Application of electric arc furnace slag. Proccedings matrib Vela luka, island Korčula, Hrvatska (2009) 24-26.

[20] Aziz, M. M. B. A., Ratnasamy Muniandy, Khazani Abdullah, Ahmad Rodzi Mahmud, Kaida Khalid, and Alyani Ismail. "Preliminary determination of asphalt properties using microwave techniques." Journal of Engineering \& Applied Sciences 5, no. 11 (2010): 70-81.

[21] Chaurand, Perrine, Jerome Rose, Valérie Briois, Luca Olivi, Jean-Louis Hazemann, Olivier Proux, Jérémie Domas, and Jean-Yves Bottero. "Environmental impacts of steel slag reused in road construction: A crystallographic and molecular (XANES) approach." Journal of Hazardous Materials 139, no. 3 (2007): 537-542.

[22] Tang, Yu. "Effect of Slag Composition on Fatigue Life of High Speed Wheel Steel." In Advanced Materials Research, vol. 675, pp. 264-269. Trans Tech Publications Ltd, 2013.

[23] Louzi, Nawal. "Modification of Hot Asphalt Mixtures in Jordan and Syria by Using Steel Slag." Jordan Journal of Civil Engineering 159, no. 699 (2012): 1-14. 
[24] Skok, Eugene L., Eddie N. Johnson, and Amir Turk. "Asphalt pavement analyzer (APA) evaluation." (2002).

[25] Muniandy, R., E. Aburkaba, L. Mahdi, and S. D. Ehsan. "Effects of mineral filler particle size and type on permanent deformation of stone mastic asphalt mixtures." GJ P\&A Sc and Technol 2012 (2012): 50-64.

[26] Hainin, Mohd Rosli, Nur Izzi Md Yusoff, Mohd Fahmi Mohammad Sabri, Mohd Azizi Abdul Aziz, Mohd Anwar Sahul Hameed, and Wasid Farooq Reshi. "Steel slag as an aggregate replacement in Malaysian hot mix asphalt." ISRN Civil Engineering 2012 (2012).

[27] Hamzah, Meor O., and T. C. Yi. "Effects of temperature on resilient modulus of dense asphalt mixtures incorporating steel slag subjected to short term oven ageing." World Academy of Science, Engineering and Technology 46 (2008): 221-225.

[28] Joshi, Vijay K., and Richard M. Arenicz. "Use of Slag: A Direct Benefit to Our Environment." National Slag Association, MF (2011): 203-11.

[29] Khan, Ziauddin A., Rezqallah H. Malkawi, Khalaf A. Al-Ofi, and Nafisullah Khan. "Review of steel slag utilization in Saudi Arabia." In The 6th Saudi Engineering Conference, KFUPM, Dhahran, Saudi Arabia, vol. 3, pp. 369-381. 2002.

[30] Wilson, Douglas J., and Philippa M. Black. "Comparison of skid resistance performance between greywackes and melter slag aggregates in New Zealand." In International Conference Managing Road and Runway Surfaces to Improve Safety, pp. 11-14. 2008.

[31] Asi, Ibrahim M. "Evaluating skid resistance of different asphalt concrete mixes." Building and Environment 42, no. 1 (2007): 325-329.

[32] Hunt, Liz, and Glenn E. Boyle. Steel slag in hot mix asphalt concrete. No. OR-RD-00-09. 2000.

[33] Wu, Shaopeng, Yongjie Xue, Qunshan Ye, and Yongchun Chen. "Utilization of steel slag as aggregates for stone mastic asphalt (SMA) mixtures." Building and environment 42, no. 7 (2007): 2580-2585.

[34] Wang, George, Yuhong Wang, and Zhili Gao. "Use of steel slag as a granular material: volume expansion prediction and usability criteria." Journal of Hazardous Materials 184, no. 1-3 (2010): 555-560. 